ALIRNATA

Paper ID \#6097

Enhancing Student Learning in a Graduate Course in Manufacturing Technology

Dr. Bimal P. Nepal, Texas A\&M University 


\title{
ENHANCING STUDENT LEARNING IN A GRADUATE COURSE IN MANUFACTURING TECHNOLOGY
}

\begin{abstract}
The manufacturing enterprises are facing fierce competition due to globalized marketplace and changing customer demands. In order to stay competitive, the companies are widely adopting modern manufacturing management principles such as lean and six-sigma. This has had repercussion in the academic curriculum as well. More manufacturing engineering and manufacturing technology programs alike have courses in lean manufacturing and six-sigma quality management as a result. However, the actual impact of these efforts can be realized only when an academic unit's "product" (students) can deliver it at the workplace. In order to build a positive student learning in the $21^{\text {st }}$ century world, one needs to follow different and more innovative and active learning approach in the classroom. This paper presents a conceptual framework of student learning lifecycle during a semester long course. The paper uses two distinct case examples to demonstrate the proposed framework for enhancing the student learning in a class room. First example is drawn from a graduate class in manufacturing technology with small class size whereas the second example is from a relatively large sized undergraduate class in industrial distribution program. Both classes are related to quality management and lean six-sigma principles. Few teaching tools used in the proposed framework include interactive lecture notes, videos, daily quizzes, application oriented HW assignment, article review, and real-world case analysis. The paper presents results of student feedback on the various teaching tools used in those classes. The results of the survey showed that student's have learned more as a result of the teaching techniques used. Although individual uses of these techniques are not new, this paper presents a noble approach to enhance the student learning by integrating them into a learning lifecycle framework. In addition to students learning, the paper discuses benefits of integration of applied research and teaching for faculty scholarship and curriculum improvement.
\end{abstract}

\section{Introduction}

The role of engineering technology program, as often described in the engineering education literature, is to produce "trained" engineers so that they can actually begin working on day one of their job. By design, the engineering technology programs are supposed to focus more on the applied research and hands-on techniques ${ }^{1}$ than on mathematical proof of theories. According to the feedbacks the author received in the student evaluations (at least in the engineering technology and equivalent programs), they are more interested in hands-on examples than in 
theoretical stuffs. In other words, Technology students typically want to hear more about the immediate applicability of the curriculum where as pure Engineering students may be equally interested in the theory behind an application. Therefore, most of the graduate courses nowadays have a project component in it to provide the students with the exposure to real world problems. While this is certainly a key to boost their knowledge and skills of problem solving, it does not necessarily provide the opportunity to learn from the "success" or "mistakes" of others. In order to do so, one has to review or benchmark how others have implemented the same concept.

Different types of learning approaches are practiced in higher education. The traditional approach of learning is topic-based learning ${ }^{2}$. In this approach, an instructor delivers lectures on series of topics, most likely from a textbook. Although textbook topics provide the essential elements of the subject matter, how much a student can learn in the class from this approach depends largely upon how a lecture is designed or delivered. The knowledge transmission from topic based learning can be enhanced if the course is delivered in an interactive ways with lots of in-class exercises. Moreover, educators argue that the topic based approach has little correlation with what is the contemporary need of the industry and they suggest the project-based learning to bridge that gap ${ }^{3,4}$.

This paper presents a framework for student learning that consists of combination of tools that are used in both topic-based and project-based learning approach. In addition, it also describes course design and delivery techniques along with recommended timelines for incorporating different teaching tools during a semester. In the end, it presents results of student surveys that were conducted in two different course settings-one each for graduate and undergraduate class.

\section{Proposed learning framework}

Exhibit 1 depicts the proposed framework for enhancing student learning. It consists of four types of learning that happens over the semester long course, which the author defines as the student learning lifecycle. Each type of learning and their timeline are briefly described in the following sections. 
Exhibit 1: A framework for enhancing student learning in a classroom setting

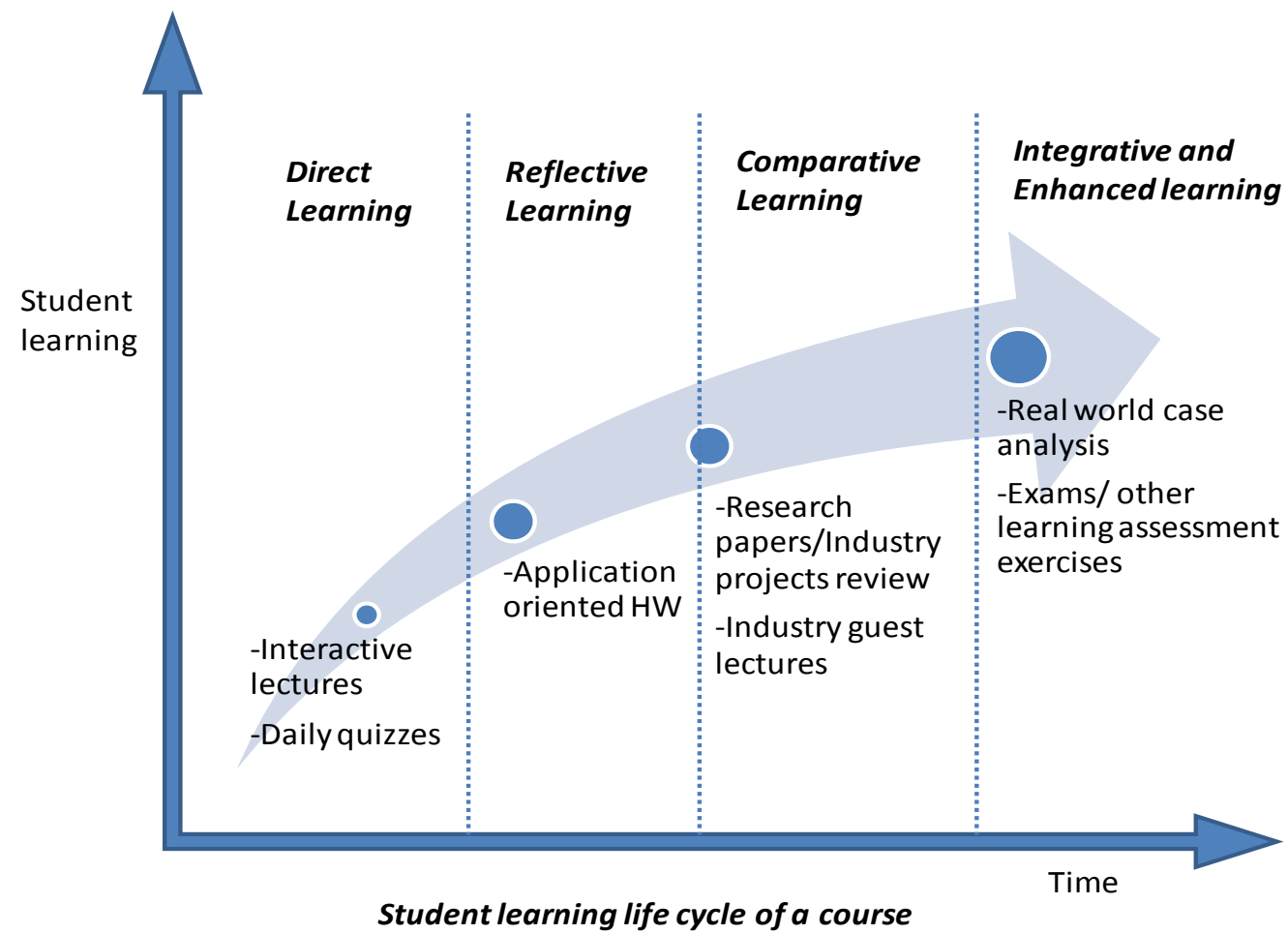

\section{A. Direct learning}

Direct learning happens when an instructor delivers the lecture. Unlike the traditional PowerPoint presentations, this instructional delivery involves more in-class exercises and daily quizzes. Such exercises and quizzes need not be long but have to be thought provoking and reinforcing the concepts that have been just presented. For example, if we are discussing Deming's quality theory in the class then the discussion or quiz questions should cover the flip side of some his 14 points. Deming suggested that one should not focus on objective performance goal. It is certainly very debatable concept. So the instructor can ask the potential managerial implications of the same. How it relates with modern quality management principles like six-sigma, which in addition to targeting an aggressive quality level also emphasizes on a business case with clear goal. Does that mean these two principles are at odds? Do they cross over at some point? Such exercise can be held anytime during the class. It is suggested that there should be some credits towards their final grades for these activities. That way, in addition to enhancing student learning, it can also boost attendance in the class particularly if it is not mandatory otherwise.

\section{B. Reflective learning}

Reflective learning takes place outside the classroom when a student tries to solve problems like homework assignments by using the concepts discussed in the class. Essentially, he or she 
reflects on what has been discussed in the class or in the textbook. Therefore, the homework problems should be designed in such a way that it expands the topical boundary. In other words, we can have two types of assignments- first set of questions can be more direct questions solely based on the lecture whereas the other questions should encourage students to think beyond what has been presented in the class. Depending upon the nature of the course, a combination of essays, numerical problems embedded with managerial interpretations/insights, and textbook case studies are good examples of reflective homework problems. While the actual number of assignment is an instructor's preference, it makes sense to give one reflective homework assignment at the end of each major topic.

\section{Comparative learning}

In this mode of learning, knowledge transmission takes place when we try to put things into perspective by brining the real world examples into the class rooms. There are numerous ways we can achieve this learning objective. As shown in Figure 1, reviewing a published research article (mainly case study type), or reviewing an industry project by inviting a guest speaker to the class. When students do that they can compare their knowledge of problem solving tools with how the research article or the industry guests have applied to solve their problems. This process can also be described as benchmarking. This exposes any challenges of the textbook concepts in the real world, particularly with respect to implementations. The most common challenges are: first the availability of data; and next, potential organizational changes that come with the implementation of new processes. The research case study or guest speakers can shed light on these practical aspects. They will talk about what kind of "tweaking" they had to do in order to design or implement the new process. This process not only helps motivate the students to learn the course but also expands their knowledge horizon beyond the standard textbook problems. In the undergraduate quality class the author is teaching, he invites two to three guest speakers from industry representing both manufacturing and distribution. These guest speakers talk about how they have implemented quality management framework and techniques like ISO9000, control charts, lean and six-sigma projects. Each speaker will focus on one major area. The scheduling of the guest lecturer is aligned with the class schedule so the students will have the background information prior to the industry presentation.

\section{Integrative and enhanced learning}

This is the most important phase of student learning lifecycle. In this mode, the students try to use an integrated approach to solve the problems. It requires integrating knowledge of multiple courses from multiple sources like internship, research, and expert interviews depending upon the case. Examples of integrative learning include working on real-world case analysis and semester projects. Although access to real world problems for project and case analysis may vary depending upon the class and instructor's connection with the industry, there are other sources to get the real world teaching cases. Many university publishing houses like Harvard Business

School and Darden School of Business at the University of Virginia publishes teaching cases that 
are created for classroom discussions. Furthermore, many times there are full-time working students in a graduate class. Instructor can encourage those students to work on their own industry problems, where possible. For example, in one of the cases this paper presents, over $75 \%$ of the students were full time employees so they worked on their company problems. In other undergraduate class, the author worked with an oil and gas company and developed a teaching case. The case analysis culminates into a short presentation and written report. One way to encourage students to think outside the box and integrate the knowledge they gained from other sources is to design the grading rubrics that reward creativity and thoughtful managerial implications. Lastly, one can argue that a rigorous assessment technique like comprehensive final exam also encourages students to study seriously. The idea here is very simple, the more they study, the more they will know the subject. However, to the best of our knowledge, there is no direct correlation between a difficult exam and student learning.

\section{Case examples}

In this section, two case examples are presented in which the proposed learning framework has been implemented successfully. While both examples represent the quality management course, both classes were different in many ways. First, one was a small sized graduate class in manufacturing technology whereas the second one was a large sized undergraduate class in industrial distribution program. Since both programs fell under the umbrella of engineering technology discipline, the students' backgrounds and expectations were very similar, that is a greater focus on the application than the theory building. In order to assess the impact of the proposed framework on their learning, student feedbacks were collected on the last day of class. They were asked of questions about their perceived learning from the course. The survey was anonymous and voluntary. Since the objective of the survey was to identify the opportunities for improvement, students were encouraged to be as much critical of the course as possible. Following sections present the key findings of the surveys in the both classes.

\section{A. Case I- graduate course on quality and productivity}

As mentioned earlier, this was a graduate level course in manufacturing technology program offered at a regional campus of one of the leading university systems in the Midwestern USA. The course topics primarily included quality management philosophies and frameworks ${ }^{2}$ such as that of Deming, Juran, Ishikawa, Feigenbum, and ISO 9000-2000. It also included lean manufacturing and six sigma quality management methodologies. The course was divided into three major modules: first, quality management philosophies and frameworks; second, lean manufacturing principles; and lastly, the six sigma methodologies such as DMAIC and DFSS. Apart from regular discussion of these topics, the course also included reviews of actual industry projects on lean manufacturing and six-sigma implementation, published research articles around these topics, and one semester project on real world problem. 


\section{B. Survey of student learning of the graduate class}

As mentioned earlier, the survey was voluntary and anonymous. The students were asked about how they viewed the impact of different components of course such as case study, article reviews, and project in addition to the regular texts on their learning. The questions were both open ended and close ended. For close ended questions, five point Likert scale was used. The summary of the survey results is shown in Exhibit 2.

\section{Exhibit 2: Results of student learning survey}

\begin{tabular}{|l|c|}
\hline 1. Article presentation & Average Score out of 5 \\
\hline Broadened my understanding of the topic & 3.8 \\
\hline Learned new things that was not necessarily covered in the class & 3.7 \\
\hline It is a good technique to enhance student's learning & 4.0 \\
\hline It is a burden to student that does not help & 1.6 \\
\hline It was a too easy group exercise that did not add any new value to my learning & 1.7 \\
\hline 2. Case Study & \\
\hline Broadened my understanding of the topic & 4.1 \\
\hline Learned new things that was not necessarily covered in the class & 4.4 \\
\hline It is a good technique to enhance student's learning & 4.1 \\
\hline It is a burden to student that does not help & 1.4 \\
\hline Provided real world prospective of the subject & 3.9 \\
\hline It was a too easy group exercise that did not add any new value to my learning & $\mathbf{1 . 6}$ \\
\hline 3. Final Project & \\
\hline Broadened my understanding of the topic & 4.0 \\
\hline Learned a lot from project experience & 4.1 \\
\hline It is a burden to student that does not help & $\mathbf{1 . 7}$ \\
\hline Provided real world prospective of the subject & $\mathbf{4 . 1}$ \\
\hline 4. Presentation and Peer Review Techniques & 3.8 \\
\hline Having multiple presentations helped my public speaking & 4.0 \\
\hline Presentations indeed helped me learn better & 3.3 \\
\hline Peer review techniques helped to improve my presentation skills & 3.1 \\
\hline Its evaluation criteria are scientific and I have learned something new & $\mathbf{4 . 1}$ \\
\hline It helped me organize my thoughts for a professional presentation & $\mathbf{2 . 1}$ \\
\hline It is a burden to student that does not help & 3.9 \\
\hline 5. HW and Exams & $\mathbf{1 . 9}$ \\
\hline HW problems challenged my understanding of the course & $\mathbf{2 . 1}$ \\
\hline Were too easy did not expand my understanding & $\mathbf{2 . 3}$ \\
\hline HW problems were too abstract and did not make any practical sense & $\mathbf{3 . 5}$ \\
\hline Exam problems were too abstract and did not make any practical sense & \\
\hline Multiple type choice questions challenged my understanding of the course & \\
\hline Sc: & \\
\hline
\end{tabular}

Scale: $1=$ Strongly Disagree, 5 = Strongly Agree

The survey results clearly demonstrated that students had tremendous impact of the proposed techniques on their learning. On the question of "learned new things that are not necessarily covered in the class", the students voted roughly 4 out of 5 in each category, that is, article presentation, case study, and final project. Even on homework, students agreed that the problems have challenged their knowledge. On another common question "It is a good technique to 
enhance student's learning”, the average score was more than 4 (out of five) for all three categories- article presentation, case study, and final project. As demonstrated by the survey, the students appreciated the real world perspective provided by these components of the course.

The survey results provided the perceived learning. We believe the actual learning assessment is reflected on the students' grades in the course. In this particular course, the average GPA for the class was 3.6/4.0. That clearly shows a direct correlation between students' perceived learning and their performance in the course.

Below are the excerpts from student's comments on the evaluation of instruction.

On question, "what did you like most about this course". These were the some of the comments:

"I found in-class discussions helpful in deepening my understanding of the material"

"Quality system and real world problems, Research paper"

"Good subject material"

"Practical, ready to apply in industry"

"The ability to immediately apply knowledge to real-world scenarios"

"The group projects have been the most enjoyable part".

\section{Case II- undergraduate course on quality processes for distribution}

This course also had very similar modules as those of the graduate class described earlier albeit the two courses were offered at different times at different university. The undergraduate class was offered as a core course of industrial distribution program at a major university in the Southwestern USA. This program is very popular with one of the highest placement rates on the university campus. One of the reasons cited by their employers that made these students highly sought after is their preparedness to take on the problems on day one of their job. Therefore, focus of the curriculum including that of the quality class was to incorporate as much practical examples/problems as possible, which made the perfect case to adopt the proposed learning framework.

On the other hand, not all tools described in Figure 1 were used in both courses. For instance, there were no guest speakers in the graduate class so the comparative learning objective was achieved through review of published case study and industry project presentation by working students. However, in the undergraduate class, three guest speakers from different companies came and presented their case studies. Of those three, the first speakers shared the experience of implementing ISO9000, the second focus on designing and implementing customer services, and the last speaker discussed the implementation of lean and six sigma quality/process improvement techniques. The speakers were from three distinct industry types- one each from heavy 
equipment manufacturing, fluid power distribution, and luxury car dealership. There was no article review in the undergraduate class. Similarly, graduate class did not have daily quizzes. Since the graduate class size was relatively small, the instructor was able work on the problems in the class with the students.

\section{Survey of student learning in the undergraduate class}

Exhibit 3 shows the summary of the results. It shows that out of 82 students who participated in the survey, over $96 \%$ said that the daily quizzes had positive learning impact. Likewise, over $99 \%$ of them said the quizzes helped them to understand the concept. Similar responses were found about the case studies and homework assignments. Compared to other teaching tools, the industry presentations were less popular. However, over $80 \%$ of the students said that the guest speakers motivated them to learn the quality techniques discussed in the class. The slightly low response can be attributed to the presentation materials of a particular speaker than the industry presentation concept in general.

Exhibit 3: Results of the undergraduate class survey

\begin{tabular}{|c|c|c|c|c|c|c|c|}
\hline $\begin{array}{r}\text { Sr. } \\
\text { No }\end{array}$ & Question & Strongly agree & Agree & Disagree & $\begin{array}{c}\text { Strongly } \\
\text { Disagree }\end{array}$ & $\begin{array}{c}\text { Didn't have any impact } \\
\text { on my learning }\end{array}$ & $\begin{array}{c}\text { Number of positive } \\
\text { learning response }\end{array}$ \\
\hline 1 & $\begin{array}{c}\text { The in-class quizzes have made a positive impact } \\
\text { on my learning }\end{array}$ & $51.2 \%$ & $45.1 \%$ & $2.4 \%$ & $0.0 \%$ & $1.2 \%$ & $96 \%$ \\
\hline 2 & $\begin{array}{c}\text { The in-class quizzes have helped me understand } \\
\text { the concept discussed in the class }\end{array}$ & $57.3 \%$ & $41.5 \%$ & $1.2 \%$ & $0.0 \%$ & $0.0 \%$ & $99 \%$ \\
\hline 3 & $\begin{array}{c}\text { The guest lectures have further motivated me to } \\
\text { learn the quality techniques discussed in the class }\end{array}$ & $26.8 \%$ & $57.3 \%$ & $8.5 \%$ & $0.0 \%$ & $7.3 \%$ & $84 \%$ \\
\hline 4 & $\begin{array}{c}\text { The case studies have provided me with a valuable } \\
\text { learning experience }\end{array}$ & $34.1 \%$ & $58.5 \%$ & $2.4 \%$ & $0.0 \%$ & $4.9 \%$ & $93 \%$ \\
\hline 5 & $\begin{array}{c}\text { The HW assignments have helped me understand } \\
\text { the concepts discussed in the class and relate those } \\
\text { with the real world examples }\end{array}$ & $64.6 \%$ & $34.1 \%$ & $1.2 \%$ & $0.0 \%$ & $0.0 \%$ & $99 \%$ \\
\hline
\end{tabular}

When asked to list the two reasons why they liked the daily quizzes, homework assignments, or case study, the student responses were like "hands on", "clear objective”, " grade booster", "real world examples", "good success on exams”, and "chance to use class topic knowledge”.

\section{Faculty scholarship and curriculum improvement}

In addition to improving student learning, the proposed teaching approach has helped the faculty member in his scholarly activities. First, it provided access to real world data to the faculty. He and the students have extended the class project work and eventually been able to publish two joint authored articles in peer reviewed journals. Both of the journal articles were based on the graduate class projects. On the undergraduate side, the visiting guest speakers have also provided 
data for his on-going research. In addition, he has completed a white paper to deal with international shipping damage for the heavy equipment manufacturing company of which production manager came and spoke to the industrial distribution class. The white paper is likely to result into a funded research project for the faculty.

From the curriculum improvement standpoint, student feedbacks were very important. The survey results have encouraged the instructor to incorporate this approach in his other courses as well. For example, the undergraduate course syllabus was modeled after graduate class which was offered prior to that. The survey also included open ended questions in which students were asked to provide any suggestion to improve the course. The author has used those suggestions to improve his courses. Furthermore, the author regularly seeks feedbacks from his guest speakers to include the current trend and needs of the industry. Lastly, considering hands-on approach in the classroom prepares the graduates to implement the concepts immediately at the workplace without any additional training ${ }^{5}$.

\section{Conclusions}

A conceptual framework of student learning lifecycle during a semester long course has been presented. The proposed framework consisted of combination of tools that are used in both topicbased and project-based learning approach. The key teaching tools used in the proposed framework included interactive lecture notes, videos, daily quizzes, application oriented HW assignment, article review, and real-world case analysis. Two case examples were utilized to demonstrate the benefits and implementation of proposed framework for enhancing the student learning in a class room. First example was drawn from a graduate class in manufacturing technology whereas the second example was from an undergraduate class in industrial distribution program. Both classes were taught by the same instructor and were related to quality management and lean six-sigma principles. On the other hand, the class size and academic programs were totally different. Most importantly, results of the survey conducted at the end of the both classes demonstrated a positive impact of the proposed framework on student learning. Lastly, the proposed teaching framework has been beneficial to the faculty member as well in

terms getting access to real world industry data thereby working on the research paper and industry funded research projects.

\section{BIBLIOGRAPHY}

1. Gadalla, M., "Curriculum analysis of industrial technology, engineering technology and engineering manufacturing programs in a single educational environment”, Proceedings 
of the 2007 the American Society for Engineering Education Annual Conference Exposition.

2. Yousuf, A., Mustafa, M., Cruz, A. D.L. (2010). Project based learning, Proceedings of the 2010 American Society for Engineering Education Annual Conference \& Exposition, June 20-23, Louisville, KY, USA.

3. Perrenet, J.C., Bouhuijs, P.A.J. and Smits, J.G.M.M., 2000. The Suitability of ProblemBased Learning for Engineering Education: Theory and Practice, Teaching Higher Education, 5 (3), 345-358.

4. Bayles, T.M. (2005). Project based learning design pro projects for introduction to engineering design courses, Proceedings of the 2005 American Society for Engineering Education Annual Conference \& Exposition, June 12-15, Portland, OR, USA.

5. Conard, J., "Determining how to teach project management concepts to engineers", Proceedings of the 2006 American Society for Engineering Education Annual Conference Exposition. 